\title{
Impact of epilepsy surgery on development of preschool children: identification of a cohort likely to benefit from early intervention
}

\author{
Hillary A. Shurtleff, PhD, ABPP,, Dwight Barry, PhD, ${ }^{3}$ Timothy Firman, BS, ${ }^{2}$ \\ Molly H. Warner, PhD, ABPP, ${ }^{1,2}$ Rafael L. Aguilar-Estrada, MD, ${ }^{4}$ Russell P. Saneto, DO, PhD, ${ }^{1,5}$ \\ John D. Kuratani, MD, ${ }^{1,5}$ Richard G. Ellenbogen, MD, ${ }^{6}$ Edward J. Novotny, MD, ${ }^{1,5}$ and \\ Jeffrey G. Ojemann, MD ${ }^{6}$
}

\begin{abstract}
Departments of ${ }^{1}$ Neurology, ${ }^{5}$ Pediatrics, and ${ }^{6}$ Neurological Surgery, University of Washington School of Medicine; ${ }^{2} P$ sychiatry, Seattle Children's Hospital; ${ }^{3} \mathrm{Health}$ Informatics, Group Health, Seattle, Washington; and ${ }^{4}$ Hospital Escuela Universitario, UNAH, Tegucigalpa, Honduras
\end{abstract}

\begin{abstract}
OBJECT Outcomes of focal resection in young children with early-onset epilepsy are varied in the literature due to study differences. In this paper, the authors sought to define the effect of focal resection in a small homogeneous sample of children who were otherwise cognitively intact, but who required early surgical treatment. Preservation of and age-appropriate development of intelligence following focal resection was hypothesized.
\end{abstract}

METHODS Cognitive outcome after focal resection was retrospectively reviewed for 15 cognitively intact children who were operated on at the ages of 2-6 years for lesion-related, early-onset epilepsy. Intelligence was tested prior to and after surgery. Effect sizes and confidence intervals for means and standard deviations were used to infer changes and differences in intelligence between 1) groups (pre vs post), 2) left versus right hemisphere resections, and 3) short versus long duration of seizures prior to resection.

RESULTS No group changes from baseline occurred in Full Scale, verbal, or nonverbal IQ. No change from baseline intelligence occurred in children who underwent left or right hemisphere surgery, including no group effect on verbal scores following surgery in the dominant hemisphere. Patients with seizure durations of less than 6 months prior to resection showed improvement from their presurgical baseline in contrast to those with seizure duration of greater than 6 months prior to surgery, particularly in Wechsler Full Scale IQ and nonverbal intelligence.

CONCLUSIONS This study suggests that surgical treatment of focal seizures in cognitively intact preschool children is likely to result in seizure remediation, antiepileptic drug discontinuation, and no significant decrement in intelligence. The latter finding is particularly significant in light of the long-standing concern associated with performing resections in the language-dominant hemisphere. Importantly, shorter seizure duration prior to resection can result in improved cognitive outcome, suggesting that surgery for this population should occur sooner to help improve intelligence outcomes.

http://thejns.org/doi/abs/10.3171/2015.3.PEDS14359

KEY WORDS pediatric epilepsy; surgery; outcome

$\mathrm{E}$ ARLY-ONSET epilepsy is a risk factor for cognitive impairment, $, 3,27$ and evidence suggests that morbidity is evident even very early in new-onset epilepsy. ${ }^{15}$ Risk of mental retardation is significantly increased in infants less than 24 months of age with onset of intractable epilepsy, ${ }^{36}$ and even children with later-onset epilepsy and nonintractable epilepsy are at increased risk for behav- ioral and cognitive deficits. ${ }^{5,11,15,24}$ Further, cognitive decline may occur with short duration epilepsy in pediatric patients, ${ }^{27}$ and ongoing seizures may further compromise cognition and may be associated with alterations in brain morphometry, particularly reduced white matter volume, especially in the frontal lobes..$^{10}$

At the same time, resection for the remediation of

ABBREVIATIONS AED = antiepileptic drug; DNET = dysembryoplastic neuroepithelial tumor; FSIQ = Wechsler Full Scale IQ; MTS = mesial temporal sclerosis SUBMITTED August 4, 2014. ACCEPTED March 16, 2015. INCLUDE WHEN CITING Published online July 3, 2015; DOI: 10.3171/2015.3.PEDS14359.

DISCLOSURE Dr. Saneto reports receiving research funding from Biocodex, UCB Pharma, and the Childhood Absence Epilepsy Study (NIH 5U01NS045911-08). Dr. Novotny reports being a consultant for Upsher-Smith and receiving research funding from the Epilepsy Phenome Genome Project (NIH NINDS U01NS053998) and the Early Onset Epilepsy Consortium (funded by the Pediatric Epilepsy Research Foundation). The remaining authors report that they have no conflicts of interest. 
epilepsy is well accepted..$^{19,23,33}$ However, literature evaluating cognitive outcome in young children to date has yielded contradictory and confusing results, perhaps stemming from methodological confounds. Outcome studies have yielded such varied results as 1) improved cognitive outcomes; $;, 8,19,34$ 2) slight improvement in cognition being more likely than decline, with significant declines in some children; ${ }^{37}$ 3) reversible decline in at least some children, especially following left temporal lobectomy; ${ }^{7}$ ) lack of improved outcome, with some cognitive recovery being a "bonus"; 28 5) "stabilized developmental velocity"; 6) no improvement in outcome postsurgery, ${ }^{2,30}$ with this lack of improvement theorized to be associated with an abnormal neural substrate versus seizures per se; ${ }^{30}$ and 7) no improvement, with the possibility of decline in some cases. ${ }^{1}$

Although methodological issues are beginning to be addressed in adolescents and adults, ${ }^{4}$ they have not been addressed to the same extent in children, particularly very young children. Generally, the pediatric surgical outcome literature has been muddied by heterogeneous samples, combining many factors, including 1) markedly different surgical therapies, from focal resections to hemispherectomies, $3,26,28$ 2) broad age inclusion criteria, at different developmental levels, from 6 to 17 or 18 years ${ }^{30,37}$ or 1 to 15 years ${ }^{1}$ or "all children"; 2 3) variable levels of functioning prior to resection; ${ }^{30} 4$ ) wide ranges of presurgical seizure duration; ${ }^{28}$ and 5) variable pathologies..$^{2,28}$

Because many pediatric studies have focused on different age ranges, some studies have attempted to narrow the developmental scope, but their methods have still varied from each other, making them difficult to compare. Age range samples include patients less than 6 or 7 years at surgery, ${ }^{19,28} 3$ to 7 years, ${ }^{6} 8$ to 159 months, ${ }^{34}$ less than 3 years, ${ }^{20,26}$ or 3 to 36 months. ${ }^{3}$

A number of studies ${ }^{7,21,22,29,32,37}$ have focused on temporal lobectomies and have provided important information regarding outcome following this procedure, with some variable findings. Yet, these studies, so far, have wide surgical age ranges, crossing developmental stages, as well as lengthy presurgical seizure durations, lasting many years, and do not differentiate between outcome following short versus long presurgical seizure duration. Smith and associates ${ }^{31}$ have furthered the literature by reporting on long-term outcome (mean 8.5 years postresection), but their findings may be compromised by particularly long seizure durations (mean seizure onset and mean surgery ages differ by about 10 years) prior to resection as well as the mixture of focal resections and pathologies with multilobar resections and more generalized disease.

While the above studies have provided crucial first steps in our attempts to better define pediatric epilepsy and the efficacy of resection, all of the above factors make pediatric outcome studies, particularly of young children, difficult to compare. There is a clear need to better define and study more homogeneous groups of children despite the challenges of power inherent in narrowing groups. In addition, because resection can be undertaken too late to avoid irreversible disability ${ }^{4}$ and because early cessation of epileptogenic spread from a focal onset can be crucial for the return to normal developmental trajectories, ${ }^{28}$ it is essential to identify well-defined patient groups who may particularly benefit from early surgical therapy.

We sought to narrow the scope of our evaluation to 1) focal resections; 2) a specific and narrow age range and developmental level, 2-6 years, similar to at least 1 prior study ${ }^{6}$ and corresponding with a specific developmental period previously identified by Piaget (preoperational stage, 2-6 or 7 years); and 3) patients who were not yet showing clear global cognitive deficits at the time of resection. Additionally, we examined the impact of duration of seizures prior to surgery.

\section{Methods \\ Participants}

This study was approved by the institutional review board at Seattle Children's Hospital. We retrospectively identified Seattle Children's Hospital patients who had epilepsy surgery between April 2000 and July 2012, were 2-6 years old at surgery, did not present with developmental delays or cognitive impairment, and had focal resective epilepsy surgery and pre- and postsurgical neuropsychological evaluations. These patients were selected from a larger and more heterogeneous sample of patients who did not have lesion-related epilepsy, were not functioning within average cognitive limits, and/or needed larger resections. Patients with presurgical Wechsler Full Scale IQ (FSIQ) scores of less than 80, large (e.g., multilobar or hemispherectomy) resections, and/or dual pathology were excluded. Two patients with no presurgery IQ testing were included in this study because developmental screening showed average functioning, but these patients were excluded only from pre/post comparisons due to the lack of presurgical Wechsler scores. Patients with Vineland-structured interviews were excluded from statistical analyses.

Pathology and surgical information for the 15 patients included by our protocol is summarized in Table 1 . All patients had focal resections, 6 right and 9 left hemisphere. Postsurgical MRI scans were independently reviewed to confirm areas resected. Pathology included the following: 2 DNETs (dysembryoplastic neuroepithelial tumors); 4 gangliogliomas; 2 oligodendrogliomas; 1 gliosis; 2 vascular malformations (cavernomas); 2 mesial temporal sclerosis (MTS); and 2 focal cortical dysplasias (Taylor Type IIA).

\section{Data Collection and Analysis}

Seizure duration prior to resection was identified in months for each patient via chart review of existing medical records, and postsurgical seizure outcome was determined by using Engel's criteria. ${ }^{38}$ Because there is no precedence for measuring presurgical seizure duration in young children, we arbitrarily assigned 6 months as "short" duration and anything longer as "long" duration, and in our sample the latter meant children with 18 or more months of seizure activity prior to surgery. Presurgically, all patients had seizures associated with identified lesions and were treated with at least 1 antiepileptic drug (AED), except for 1 patient who had only 1 seizure and was not on medication. The exception was included because she was expected to have continued seizures associated with her 
TABLE 1. Surgical details, postsurgical pathology, and postsurgical seizure classification

\begin{tabular}{|c|c|c|c|c|c|c|c|c|c|}
\hline \multirow[b]{2}{*}{$\begin{array}{l}\text { Case } \\
\text { No. }\end{array}$} & \multirow[b]{2}{*}{ Side } & \multirow{2}{*}{$\begin{array}{c}\text { Age at } \\
\text { Op } \\
\text { (yr, mo) }\end{array}$} & \multirow[b]{2}{*}{ Lobe } & \multicolumn{2}{|r|}{ Sz Prior to Op } & \multirow[b]{2}{*}{ Resection } & \multirow[b]{2}{*}{ Pathology } & \multicolumn{2}{|c|}{ Postop } \\
\hline & & & & $\begin{array}{l}\text { Duration } \\
\text { (mo) }\end{array}$ & Characterization & & & Mos & $\begin{array}{l}\text { Engel } \\
\text { Class }\end{array}$ \\
\hline 1 & Rt & 4,3 & Temporal & 5 & Controlled on 1 AED & Anterior temporal lobectomy & DNET & 93 & IA \\
\hline 2 & Rt & 6,5 & Temporal & 5 & Sz on 1 AED & Selective temporal lesionectomy & Oligodendroglioma & 19 & IA \\
\hline 3 & $\mathrm{Lt}$ & 5,7 & Frontal & 5 & Intractable & $\begin{array}{l}\text { Inferior frontal gyrus (triangular gyrus } \\
\quad \text { \& insula) }\end{array}$ & Cavernoma & 47 & IA \\
\hline 4 & $\mathrm{Rt}$ & 2,1 & Temporal & 19 & Sz on 1 AED & Anterior temporal lobectomy & Ganglioglioma & 47 & IA \\
\hline 5 & $\mathrm{Lt}$ & 6,6 & Temporal & 32 & Intractable & Anterior temporal lobectomy & Gliosis & 8 & IA \\
\hline 6 & $\mathrm{Lt}$ & 6,3 & Temporal & 23 & Intractable & Anterior temporal lobectomy & MTS & 131 & ID \\
\hline 7 & $\mathrm{Lt}$ & 6,2 & Temporal & 62 & Intractable & $\begin{array}{l}\text { Selective temporal lobectomy (mesial } \\
\text { resection) }\end{array}$ & MTS & 24 & IA \\
\hline 8 & Rt & 4,0 & Frontal & 2 & Intractable & $\begin{array}{l}\text { Frontal lesionectomy (inferior orbital } \\
\quad \& \text { medial gyrus) }\end{array}$ & Oligodendroglioma & 88 & IC \\
\hline 9 & $\mathrm{Lt}$ & 6,9 & Frontal & 0 & $1 \mathrm{Sz}$, no AED & $\begin{array}{l}\text { Frontal lesionectomy (medial frontal } \\
\text { gyrus) }\end{array}$ & Cavernoma & 41 & IC \\
\hline 10 & Rt & 6,0 & Frontal & 35 & Intractable & $\begin{array}{l}\text { Frontal lesionectomy (superior frontal } \\
\text { gyrus) }\end{array}$ & DNET & 68 & $\| \mathrm{A}$ \\
\hline 11 & $\mathrm{Lt}$ & 2,8 & Temporal & 2 & Sz on 1 AED & $\begin{array}{l}\text { Selective temporal lobectomy (mesial } \\
\text { resection) }\end{array}$ & Ganglioglioma & 40 & IA \\
\hline 12 & $\mathrm{Lt}$ & 6,5 & Frontal & 24 & Intractable & Middle \& superior frontal gyrus & Dysplasia, Taylor Type IIB & 36 & IA \\
\hline 13 & $\mathrm{Lt}$ & 3,1 & Temporal & 5 & Intractable & $\begin{array}{l}\text { Selective temporal lobectomy (tumor } \\
\text { \& hippocampus) }\end{array}$ & Ganglioglioma & 82 & $\mid A^{*}$ \\
\hline 14 & Rt & 1,11 & Temporal & 18 & Sz on 1 AED & Selective temporal lesionectomy & Ganglioglioma & 78 & IA \\
\hline 15 & Lt & 5,4 & Frontal & 3 & Intractable & Superior \& middle frontal gyrus & Dysplasia, Taylor Type IIB & 25 & IA \\
\hline
\end{tabular}

$\mathrm{Sz}=$ seizure.

* Except for 1 event with a very high fever.

lesion had surgical intervention not occurred. Specifically, 9 patients had seizures that were considered intractable (i.e., at least 2 AEDs had failed to control their seizures); 4 children were continuing to have seizures while on 1 AED; 1 child's seizures were controlled with 1 AED, but her parents were concerned about the cognitive effects of long-term medical treatment; and 1 patient who had 1 seizure and was not being treated with any AED required surgery for removal of a cavernoma.

The clinical protocol in the Seattle Children's Hospital Epilepsy Surgery Program specifies that children being considered for epilepsy surgery are to undergo presurgical neuropsychological evaluations, whenever possible, during the presurgical workup and, if surgery occurs, they should be evaluated at 6 months, 18 months, and 5 years postsurgery, although the actual follow-up time varies. The neuropsychological tests include a broad range of measures, even for young children, including intelligence, lateral dominance, sensory-motor, visual-spatial, language, memory, attention/executive functions, and behavioral/psychosocial/mood functions. For the purposes of our focused study, only intelligence test scores were retrospectively evaluated, as intelligence is frequently used as an outcome measure and as the heterogeneous nature of specific lesion locations precluded using other single tests.

Wechsler intelligence tests were administered to all patients, with the majority of the patients having been given the Wechsler Preschool and Primary Scale of Intel-
ligence-III and the Wechsler Intelligence Scale for Children-IV, depending upon the age of the child at the time of pre- or postoperative testing. One patient had the Wechsler Abbreviated Scale of Intelligence prior to resection, and 1 patient had the Wechsler Preschool and Primary Scale of Intelligence-Revised and the Wechsler Intelligence Scale for Children-III. Because the different Wechsler scales have different nonverbal scale names (i.e., Performance IQ versus Perceptual Reasoning Index), the label "nonverbal" was assigned, and the "verbal" label was also assigned due to different verbal scale names.

Fourteen of 15 patients completed presurgical testing between 0 and 7 months prior to resection. Twelve patients completed the Wechsler FSIQ test, with a mean score of 100 (SD 13.1). Two patients did not complete Wechsler IQ testing (due to 1 being just shy of her second birthday and 1 being too distracted in the Telemetry Unit environment), but had Vineland-structured parent interviews, with overall scores of 88 and 99; they were excluded from statistical analyses to ensure that score comparisons were all done using the same test type, but were included for descriptive purposes because they met all other enrollment conditions. Two patients did not have any testing prior to surgery, but were considered to be developmentally average.

Initial postsurgical testing occurred for 14 of 15 patients between 5 and 27 months postsurgery (11 had both pre- and postsurgical intelligence testing). Of the 15 who had postsurgical testing, 11 of those patients had testing 
within 7 months or less from surgery. One patient did not have early postsurgical testing at all, and because he was first tested at 47 months postsurgery, he was included only in the "late" postsurgery group. Three patients did not have longer-term follow-up.

Our analysis looked at 2 primary contrasts: 1) postsurgical outcomes for all patients as compared with presurgical baseline and 2) postsurgical outcomes by groupings based on a) seizure duration prior to surgery and b) surgery hemisphere, with 9 patients' resections occurring on the left side and 6 on the right side. Some patients did not have second follow-up evaluations; for those patients, we used their first (and only) follow-up score as their "postsurgery" score values. For all others, we used the scores from the second testing period.

Because of the small sample size, we used $90 \%$ biascorrected and accelerated, bootstrapped confidence intervals on means and standard deviations using 10,000 replications. The $\mathrm{p}$ values were obtained via exact permutation tests. $^{12,14}$ For effect size comparisons, we calculated the absolute difference between means (IDI), the nonparametric Vargha-Delaney $A$ measure of stochastic superiority, ${ }^{35}$ and the variance ratio. While calculating IDI is a common way to provide information on group-level responses, the $A$ measure is a recent advance that allows for comparisons at the individual level for any measurement at or above an ordinal scale; it is defined as the probability that a patient sampled randomly from 1 group will have a higher score than 1 patient sampled randomly from the other group. In effect, it can be thought of as the percentage of individuals in 1 group who might show improvement over those in the contrasting group. $A$ values of 0.50 represent no grouping effect, 0.71 is considered the lower threshold for an important effect, and 1.0 represents perfect distinction between individual outcomes in each group. Confidence intervals are not included for effect sizes so as to preclude interpretations that all values in the interval are equally likely. ${ }^{16}$ All analyses were carried out using R-3.0.2; $\mathrm{p}$ values were obtained using the coin package, ${ }^{13}$ and $A$ values were obtained using the orddom package.

\section{Results}

Good seizure outcome was observed in all patients at an average postsurgical follow-up duration of 55.1 months (SD 33.8) (see Table 1). Engel Class I seizure freedom occurred in 14 of 15 patients, with 11 patients meeting criteria for Engel Class IA, 2 patients meeting criteria for class IC, and 1 patient meeting criteria for class ID. One patient met Engel Class IIA.

Decreased need for AEDs was observed in all but 3 patients. Fourteen of 15 patients were being treated with AEDs prior to surgery, and 5 patients were receiving polytherapy. All patients, except for 1, were on AEDs at the time of the initial postsurgical testing, with 3 patients receiving polytherapy. Only 4 of 12 patients were being treated with AEDs at the time of the last postsurgical testing, with each of those 4 patients being treated with monotherapy only, and with 2 of those 4 having been on polytherapy prior to resection. The patient who had 1 seizure prior to resection did not have her AED treatment initiated until after surgery, and she was still on that medication at the last postsurgical testing despite having only 1 seizure presurgery and 1 postsurgery.

The mean presurgical Wechsler FSIQ was 100 (SD 13.1); see Table 2 for a summary of test results referenced here and in subsequent paragraphs. Initial postsurgery testing resulted in a mean FSIQ of 100 (SD 15.9). When the 3 patients who did not have postsurgical follow-up within 7 months after surgery were excluded, the remaining 12 patients in this initial test group had a mean FSIQ of 99.1 (SD 16.4). Additional testing (Table 2) occurred further out after surgery, at a mean of 41.3 (SD 23.3) months and resulted in a mean FSIQ of 106 (SD 17.7) for the 12 patients tested.

An important result is that surgical treatment did not result in intellectual decline. On average, patients did not lose cognitive abilities, with no single patient losing more than 12 IQ points, meaning that patients showed age-appropriate cognitive development. Most IQs fell within the average range or above, although several patients had low average scores, and the only patient to have a borderline FSIQ at the first postoperative testing had a low average FSIQ at the later follow-up. Following surgery, patients showed a slight improvement in mean FSIQ, verbal, and nonverbal scores when contrasting their presurgery results with their last test results, although the improvements were not statistically (FSIQ $p=0.46$, verbal $p=0.50$, and nonverbal $\mathrm{p}=0.95$ ) or practically significant (Fig. 1A and $\mathrm{B}$, Table 3). In addition, there was a fair amount of individual variability (Fig. 1A), though individuals tended to have postsurgery results similar to where they started, i.e., those with higher scores before surgery tended to have relatively higher scores afterward and vice versa. There was also no practical change in group variability for any of the 3 scores either before or after surgery.

An additional important result is that left and right hemisphere surgery location groups were not significantly different, statistically (FSIQ $\mathrm{p}=0.96$, verbal $\mathrm{p}=0.73$, and nonverbal $\mathrm{p}=0.54$ ) or practically (Fig. 2 , Table 3 ); on average, both groups improved, but the confidence limits suggest that the results are consistent with no change. Changes between groups were miniscule, with the largest change occurring between verbal scores, with the left hemisphere group scoring on average 5 points higher. Variation was essentially identical, suggesting no difference in the variability of outcomes based on surgery hemisphere; left and right verbal confidence intervals on the standard deviation of the difference also share considerable overlap.

The duration from the onset of seizures to surgery appears to have an important effect on outcomes. Patients who had surgery within 6 months of onset generally had better outcomes (Fig. 3, Table 3) compared with patients who had longer duration from the onset of seizures prior to resection. While we did not detect statistically significant differences (FSIQ $p=0.06$, verbal $p=0.44$, and nonverbal $\mathrm{p}=0.05$ ), when patients with seizure duration of less than 6 months ("short duration") prior to surgery were compared with those having a duration greater than 6 months prior to surgery ("long duration"), the balance of evidence suggests that important differences were observed between the 2 groups. Specifically, clinically important im- 


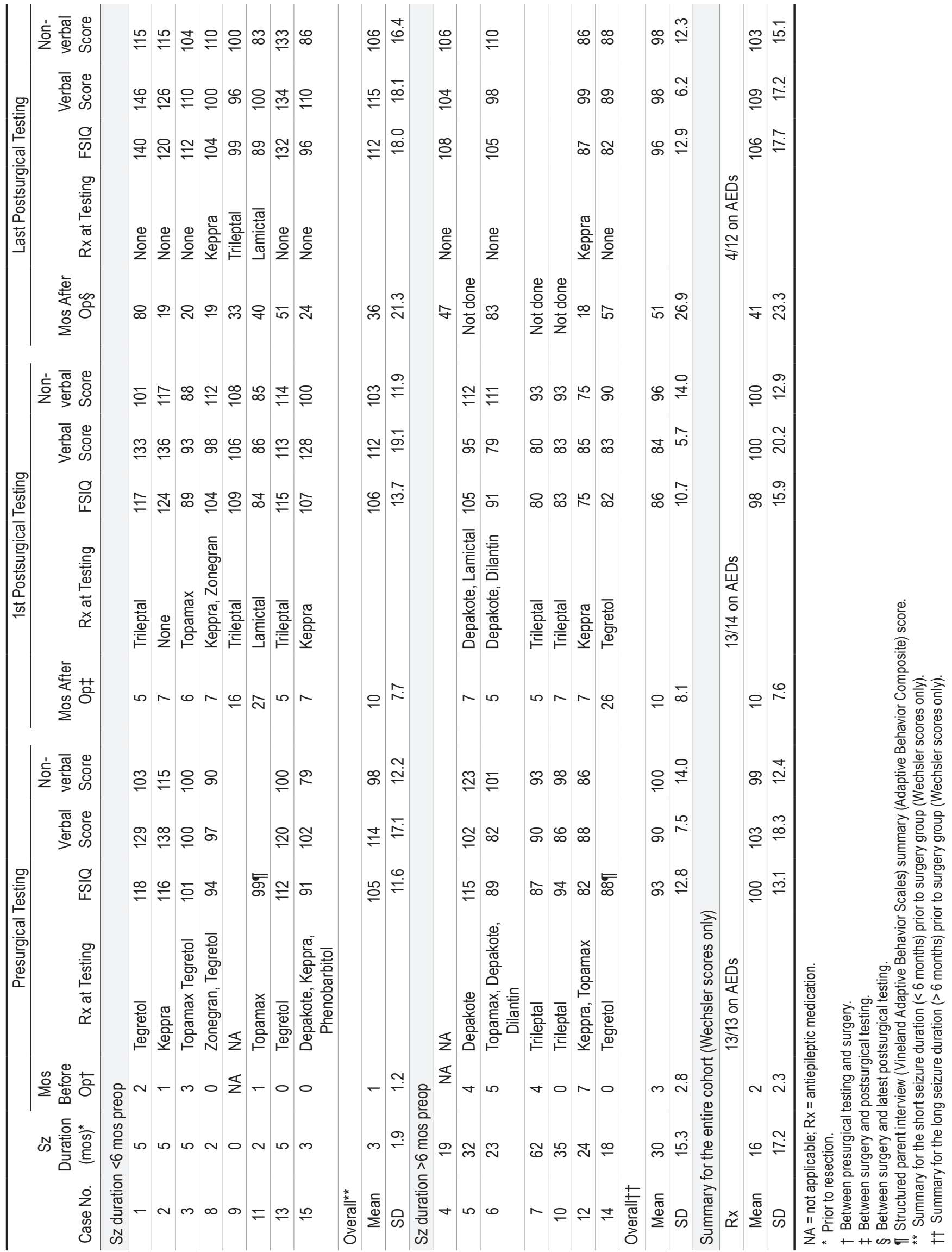


TABLE 3. Descriptive results and effect sizes for all patients

\begin{tabular}{|c|c|c|c|}
\hline Characteristic & $\mathrm{FSIQ}(90 \% \mathrm{Cl})$ & Verbal $(90 \% \mathrm{Cl})$ & Nonverbal $(90 \% \mathrm{Cl})$ \\
\hline \multicolumn{4}{|l|}{ Op groups* } \\
\hline \multicolumn{4}{|l|}{ Mean } \\
\hline Pre & $100(94-106)$ & $103(96-113)$ & $99(93-105)$ \\
\hline Post & $103(96-111)$ & $105(98-113)$ & $102(97-108)$ \\
\hline \multicolumn{4}{|l|}{ SD } \\
\hline Pre & $13.1(11.2-15.9)$ & $18.3(13.7-23.9)$ & $12.4(8.9-17.2)$ \\
\hline Post & $17.9(13.8-23.5)$ & $18.3(13.2-24.6)$ & $14.1(11.1-19.2)$ \\
\hline \multicolumn{4}{|l|}{ Range } \\
\hline Pre & 82 to 118 & 82 to 138 & 79 to 123 \\
\hline Post & 80 to 140 & 80 to 146 & 83 to 133 \\
\hline Percentage $w /$ same or improved score $(n=11)$ & 0.73 & 0.64 & 0.82 \\
\hline Absolute difference btwn means $|\mathrm{D}| \dagger$ & 3 & 2 & 3 \\
\hline Mean individual improvement $(n=11)$ & 6 & 4 & 6 \\
\hline Vargha-Delaney A & 0.52 & 0.53 & 0.57 \\
\hline Variance ratio & 1.9 & 1.0 & 1.3 \\
\hline \multicolumn{4}{|l|}{ Changes according to sidef } \\
\hline \multicolumn{4}{|l|}{ Mean change } \\
\hline $\mathrm{Lt}$ & $6(-1$ to 12$)$ & $6(-1$ to 11$)$ & $6(0-16)$ \\
\hline Rt & $6(-6$ to 15$)$ & $1(-8$ to 9$)$ & $7(-3$ to 14$)$ \\
\hline \multicolumn{4}{|l|}{ SD } \\
\hline Lt & $11.2(8.7-14.5)$ & $10.2(7.5-12.7)$ & $13.6(6.2-19.9)$ \\
\hline Rt & $13.7(7.5-19.1)$ & $12.2(6.2-16.7)$ & $11.4(7.2-14.4)$ \\
\hline \multicolumn{4}{|l|}{ Range } \\
\hline Lt & -10 to 20 & -10 to 16 & -11 to 33 \\
\hline Rt & -11 to 22 & -12 to 17 & -5 to 20 \\
\hline \multicolumn{4}{|l|}{ Percent w/ same or improved score } \\
\hline $\mathrm{Lt}$ & 0.71 & 0.71 & 0.86 \\
\hline $\mathrm{Rt}$ & 0.75 & 0.50 & 0.75 \\
\hline Absolute difference btwn means $|\mathrm{D}| \dagger$ & 1 & 5 & 1 \\
\hline Vargha-Delaney A & 0.54 & 0.61 & 0.54 \\
\hline Variance ratio & 1.5 & 1.4 & 1.4 \\
\hline \multicolumn{4}{|l|}{ Changes according to duration $\S$} \\
\hline \multicolumn{4}{|l|}{ Mean change } \\
\hline Short & $12(8-17)$ & $7(-2$ to 11$)$ & $13(6-22)$ \\
\hline Long & $-1(-9$ to 7$)$ & $1(-6$ to 9$)$ & $-1(-7$ to 3$)$ \\
\hline \multicolumn{4}{|l|}{ SD } \\
\hline Short & $7.5(5.8-9.3)$ & $10.4(4.5-14.6)$ & $12.1(7.2-16.7)$ \\
\hline Long & $11.6(6.8-14.8)$ & $11.5(9.2-14.2)$ & $7.4(4.7-10.2)$ \\
\hline \multicolumn{4}{|l|}{ Range } \\
\hline Short & 4 to 22 & -12 to 17 & 0 to 33 \\
\hline Long & -11 to 16 & -10 to 16 & -11 to 9 \\
\hline \multicolumn{4}{|l|}{ Percent w/ same or improved score } \\
\hline Short & 1.00 & 0.83 & 1.00 \\
\hline Long & 0.40 & 0.40 & 0.60 \\
\hline Absolute difference btwn means $|\mathrm{D}| \dagger$ & 13 & 5 & 14 \\
\hline Vargha-Delaney A & 0.82 & 0.60 & 0.87 \\
\hline Variance ratio & 2.4 & 0.8 & 2.7 \\
\hline
\end{tabular}



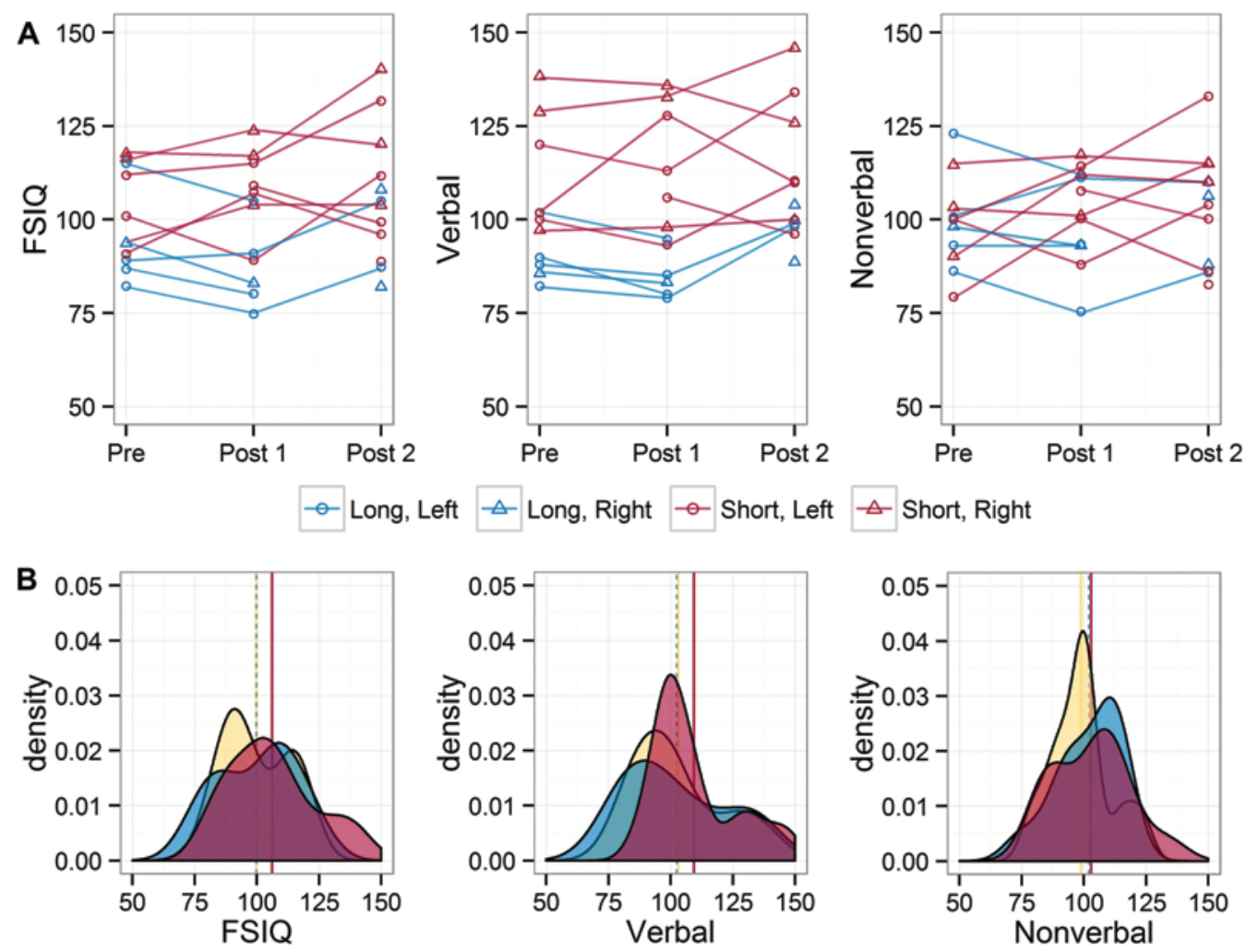

eft $\triangle$ Long, Right $\rightarrow$ Short, Left
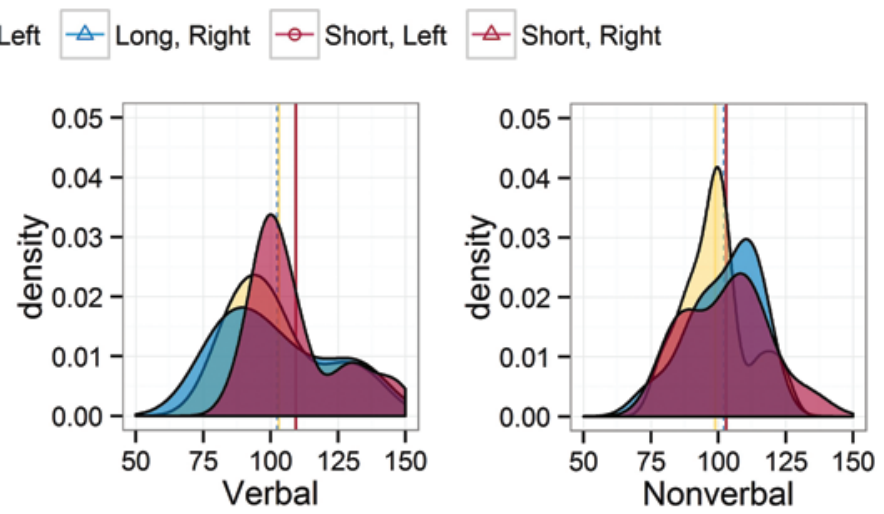

Pre-Surgery

Post Test 1

Post Test 2

FIG. 1. Individual and group changes in FSIQ, verbal, and nonverbal intelligence test scores after surgery. A: Parallel coordinates plots detail individual-level changes in test scores before (Pre) and after (Post 1, Post 2) surgery. Circles represent patients in the left-hemisphere surgery group, triangles represent those in the right-hemisphere group, red represents having surgery within 6 months of diagnosis (Short), and blue represents having surgery 18 months or more after diagnosis (Long). B: Density histograms summarize individual responses by time for each test grouping, where vertical solid lines correspond to the mean score for each time step. The vertical dashed lines represents the Post 1 time step to help distinguish it from presurgery and later postsurgery mean results.

provements for the short duration group occurred in both FSIQ and nonverbal scores; FSIQ and nonverbal scores improved by 13 and 14 points on average, respectively. The Vargha-Delaney A results for these 2 improvements suggest that patients who undergo surgery within 6 months will show improved FSIQ and nonverbal scores about $82 \%$ and $87 \%$ of the time, respectively, as compared with waiting 18 months or more for surgery after seizure onset. There was indication of a slight difference between the short and long duration groups in verbal scores, although interpretation of confidence intervals and $A$ value for this comparison suggests that this result is also consistent with no difference. The group variances for all 3 scores were also not different given the sample size; variance ratios of 3 or more are needed before one can suspect that differences in variability are a result of treatment.

\section{Discussion}

In contrast to some prior research that has shown resection in young children to be associated with subnormal intelligence, our study identified a cadre of cognitively intact young children with focal seizures and lesions on MRI who benefitted from surgical treatment. Our study group was cognitively intact at the time of resection and remained so at the time of the last follow-up, and, in addition, our patients experienced significant reduction in, and in most cases cessation of, seizure activity, with a concomitant discontinuation of AED in most cases.

Our sample represents a significantly different group as compared with prior studies for several reasons. First, because we chose a developmental group that excluded infants and toddlers, our group did not include patients in the first year of life, who are likely to have more severe disease. ${ }^{28}$ Second, resection was undertaken prior to potential cognitive decline and involved only limited focal resections. In addition, patients who needed more extensive resections, such as multilobar surgeries or hemispherectomies, and patients who were already functioning below average prior to referral for presurgical workup, were not included in this study. These latter patients likely also have worse disease, with potentially more widespread pathology of cerebral organization. To define a homogeneous group, we purposefully chose this very select sample with lesion-related seizures, precluding a more heterogeneous group that would likely include more medically intractable and non-lesion-related epilepsy. Duration from seizure onset to resection appeared to impact outcome, with the shorter duration group data suggesting more normal cog- 

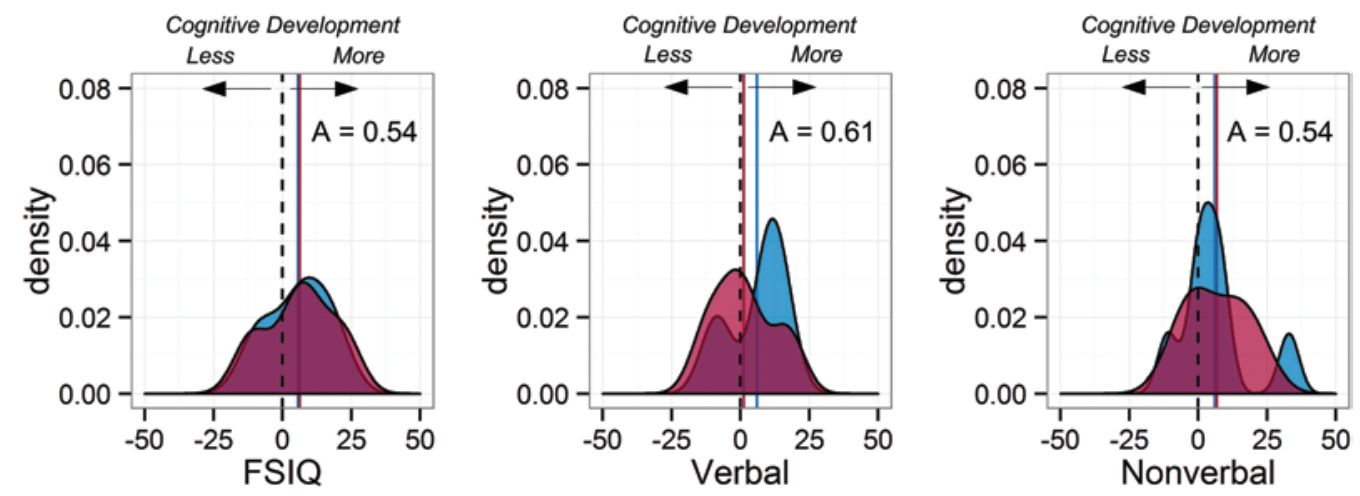

Surgery Side:

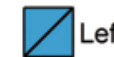

Right

FIG. 2. Comparison of density histograms for pre- and postsurgery responses shows no cognitive difference in any intelligence test score grouping based on the hemisphere of surgery. $A$ is the nonparametric Vargha-Delaney effect size measure and represents the probability that a patient sampled randomly from one group will have a higher score than one patient sampled randomly from the other group. Values greater than 0.71 suggest an important effect, while values near 0.50 suggest no effect. The vertical solid lines represent the mean change in test score for each group while the vertical dashed lines represent no change from baseline for comparison.

nitive expectations than the longer duration group. This finding is consistent with the literature that shows that ongoing refractory seizures are associated with poorer cognitive outcome. ${ }^{5,9,24}$ In contrast, the patients with short duration of seizures prior to resection had better outcomes, with more postsurgical improvement. These findings argue for earlier resection in the context of lesion-associated seizures to preserve cognitive functions.

Side of surgery, whether the left or right hemisphere, did not appear to have a differential effect on postsurgical verbal intelligence, consistent with prior findings following temporal lobectomies. ${ }^{22}$ More specifically, left hemisphere resections did not result in verbal intelligence declines and did not result in lower verbal intelligence, as compared with right hemisphere resections. This finding is particularly significant in light of the longstanding concern associated with performing resections in the lan- guage dominant hemisphere in older individuals. Though we did not report verbal memory scores, it is important to note that sustained verbal intelligence reflects normal cognitive development, including normal verbal learning or acquisition of verbal knowledge. Additional research will be important to further improve our understanding of outcome expectations, particularly within specific domains beyond intelligence.

Pathology underlying refractory seizures can significantly impact outcome, ${ }^{22}$ and we, therefore, excluded patients with dual structural pathology and attempted to include only focal and benign pathologies, including DNETs, gangliogliomas, oligogliomas, and cavernomas. Cortical dysplasias vary, and we included only Type IIb dysplasias because previous work by Krsek and associates has shown that the Type IIb cortical dysplasias involve more focal pathology and usually have better postsurgical outcome, as
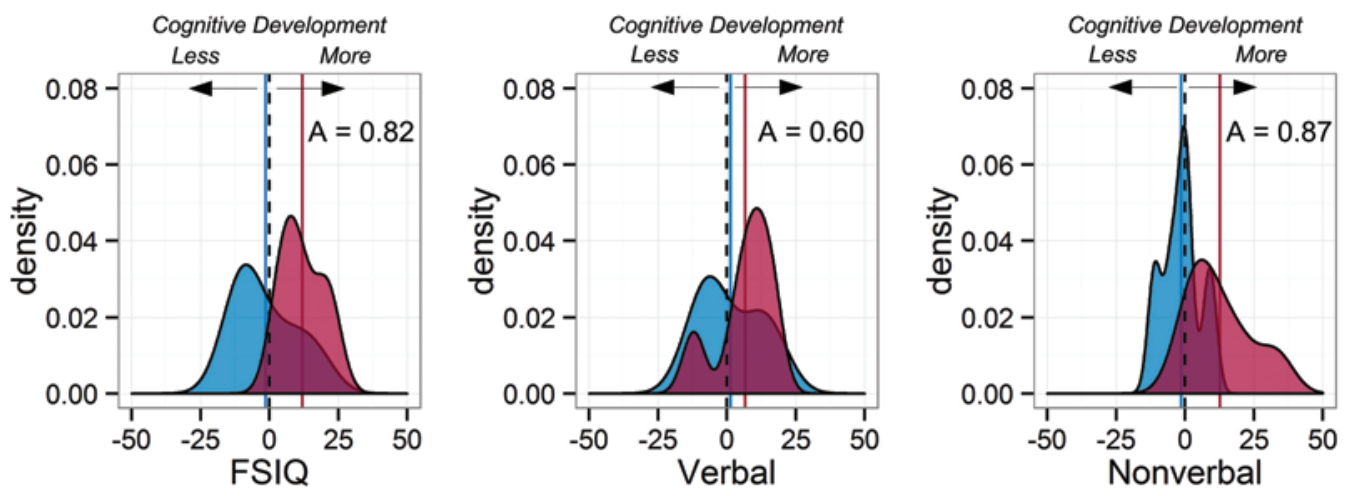

Seziure Duration Before Surgery:

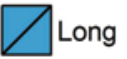

FIG. 3. Comparison of density histograms for pre- and postsurgery responses show a potential cognitive benefit in FSIQ and nonverbal intelligence test scores for subjects in the group that received surgery within 6 months of initial diagnosis (short group) as compared with those who received it more than 18 months after diagnosis (long group). $A$ is the nonparametric Vargha-Delaney effect size measure, and represents the probability that a patient sampled randomly from one group will have a higher score than one patient sampled randomly from the other group. Values greater than 0.71 suggest an important effect, while values near 0.50 suggest no effect. The vertical solid lines represent the mean change in test score for each group while the vertical dashed lines represent no change from baseline for comparison. 
contrasted with Type I, which involves more widespread disease. ${ }^{18}$ Two patients in our sample had MTS, and it could be argued that these cases should not have been included as MTS might not be as "focal" as once thought, given Kaaden and Helmstaedter's findings that earlier onset temporal lobe epilepsy may be associated with abnormalities or dysfunction beyond the MTS. ${ }^{17}$ Given their findings, it is possible that some MTS patients have "overlooked" focal cortical dysplasias, particularly Type I, and thus our 2 MTS patients might represent worse disease and have worse outcomes over time. Despite this potential concern relative to our 2 MTS patients, our longer-term follow-up data are consistent with previous literature ${ }^{7}$ showing that recovery and improvement in functioning can be appreciated at longer-term follow-up after surgical treatment, at least with follow-ups greater than 1 year postsurgery. Our diverse sample of pathology did not allow for conclusions based on lesion type.

This study is limited by the small number of patients, by not addressing AED effects, and by the lack of long-term outcome measurement. Because of the small sample size, results with high $\mathrm{p}$ values cannot be interpreted as "no effect"; at best, we can say that there is either no statistically significant effect or that if there is a statistically significant effect, the study was not powerful enough to detect it. Given the large practical effect sizes detected in this study, this is an important point to realize for future research, especially given how difficult it is to find large numbers of subjects that meet this set of criteria. In addition, also due in part to our small number of included patients, we were not able to adequately parse out specific medication effects, which is important because AEDs can have deleterious cognitive effects particularly in children. ${ }^{25}$ This issue should certainly be addressed in future studies to explore the specific impacts of AEDs on cognitive outcomes associated with surgeries. We intend to address the issues of very long-term outcomes and medication effects in the future.

\section{Conclusions}

This study suggests that early resective epilepsy surgery for seizure remediation in very young, cognitively intact patients can result in seizure reduction/control with AED discontinuation and also preservation of cognitive abilities across verbal and nonverbal domains. Earlier age at resection, intact cognitive functioning prior to resection, short seizure duration prior to resection, focal ictal onset, and focal findings on MRI suggesting lower likelihood of diffuse cerebral pathology are all factors that may be essential for optimal outcome. Although the sample size is small, our study suggests that surgical treatment for refractory epilepsy in this young group is optimal earlier-within 6 months from diagnosis - than has previously been the norm. At the same time, longer-term follow-up of these children will be important to document whether these advantages persist beyond childhood.

\section{References}

1. Chieffo D, Lettori D, Contaldo I, Perrino F, Graziano A, Palermo C, et al: Surgery of children with frontal lobe lesional epilepsy: neuropsychological study. Brain Dev 33:310-315, 2011
2. D'Argenzio L, Colonnelli MC, Harrison S, Jacques TS, Harkness W, Vargha-Khadem F, et al: Cognitive outcome after extratemporal epilepsy surgery in childhood. Epilepsia 52:1966-1972, 2011

3. Dunkley C, Kung J, Scott RC, Nicolaides P, Neville B, Aylett SE, et al: Epilepsy surgery in children under 3 years. Epilepsy Res 93:96-106, 2011

4. Engel J Jr, McDermott MP, Wiebe S, Langfitt JT, Erba G, Gardiner I, et al: Design considerations for a multicenter randomized controlled trial of early surgery for mesial temporal lobe epilepsy. Epilepsia 51:1978-1986, 2010

5. Fastenau PS, Johnson CS, Perkins SM, Byars AW, deGrauw TJ, Austin JK, et al: Neuropsychological status at seizure onset in children: risk factors for early cognitive deficits. Neurology 73:526-534, 2009

6. Freitag H, Tuxhorn I: Cognitive function in preschool children after epilepsy surgery: rationale for early intervention. Epilepsia 46:561-567, 2005

7. Gleissner U, Sassen R, Lendt M, Clusmann H, Elger CE, Helmstaedter C: Pre- and postoperative verbal memory in pediatric patients with temporal lobe epilepsy. Epilepsy Res 51:287-296, 2002

8. Helmstaedter C: Neuropsychological aspects of epilepsy surgery. Epilepsy Behav 5 (Suppl 1):S45-S55, 2004

9. Helmstaedter C, Kockelmann E: Cognitive outcomes in patients with chronic temporal lobe epilepsy. Epilepsia 47 (Suppl 2):96-98, 2006

10. Hermann BP, Dabbs K, Becker T, Jones JE, Myers y Gutierrez A, Wendt G, et al: Brain development in children with new onset epilepsy: a prospective controlled cohort investigation. Epilepsia 51:2038-2046, 2010

11. Hermann BP, Jones JE, Sheth R, Koehn M, Becker T, Fine J, et al: Growing up with epilepsy: a two-year investigation of cognitive development in children with new onset epilepsy. Epilepsia 49:1847-1858, 2008

12. Hothorn T, Hornik K, van de Wiel MA, Zeileis A: A Lego system for conditional inference. Am Stat 60:257-263, 2006

13. Hothorn T, Hornik K, van de Wiel MA, Zeileis A: Implementing a class of permutation tests: The coin package. $\mathbf{J}$ Stat Softw 28(8):1-23, 2008

14. Hunter MA, May RB: Statistical testing and null distributions: what to do when samples are not random. Can J Exp Psychol 57:176-188, 2003

15. Hutchinson E, Pulsipher D, Dabbs K, Myers y Gutierrez A, Sheth R, Jones J, et al: Children with new-onset epilepsy exhibit diffusion abnormalities in cerebral white matter in the absence of volumetric differences. Epilepsy Res 88:208-214, 2010

16. Jackson CH: Displaying uncertainty with shading. Am Stat 62:340-347, 2008

17. Kaaden S, Helmstaedter C: Age at onset of epilepsy as a determinant of intellectual impairment in temporal lobe epilepsy. Epilepsy Behav 15:213-217, 2009

18. Krsek P, Maton B, Korman B, Pacheco-Jacome E, Jayakar P, Dunoyer C, et al: Different features of histopathological subtypes of pediatric focal cortical dysplasia. Ann Neurol 63:758-769, 2008

19. Lippé S, Bulteau C, Dorfmuller G, Audren F, Delalande O, Jambaqué I: Cognitive outcome of parietooccipital resection in children with epilepsy. Epilepsia 51:2047-2057, 2010

20. Loddenkemper T, Holland KD, Stanford LD, Kotagal P, Bingaman W, Wyllie E: Developmental outcome after epilepsy surgery in infancy. Pediatrics 119:930-935, 2007

21. Mabbott DJ, Smith ML: Memory in children with temporal or extra-temporal excisions. Neuropsychologia 41:995-1007, 2003

22. Miranda C, Smith ML: Predictors of intelligence after temporal lobectomy in children with epilepsy. Epilepsy Behav 2:13-19, 2001 
23. Mohammed HS, Kaufman CB, Limbrick DD, Steger-May K, Grubb RL Jr, Rothman SM, et al: Impact of epilepsy surgery on seizure control and quality of life: a 26-year follow-up study. Epilepsia 53:712-720, 2012

24. Oostrom KJ, Smeets-Schouten A, Kruitwagen CL, Peters AC, Jennekens-Schinkel A: Not only a matter of epilepsy: early problems of cognition and behavior in children with "epilepsy only"-a prospective, longitudinal, controlled study starting at diagnosis. Pediatrics 112:1338-1344, 2003

25. Ortinski P, Meador KJ: Cognitive side effects of antiepileptic drugs. Epilepsy Behav 5 (Suppl 1):S60-S65, 2004

26. Ramantani G, Kadish NE, Strobl K, Brandt A, Stathi A, Mayer H, et al: Seizure and cognitive outcomes of epilepsy surgery in infancy and early childhood. Eur J Paediatr Neurol 17:498-506, 2013

27. Rantanen K, Eriksson K, Nieminen P: Cognitive impairment in preschool children with epilepsy. Epilepsia 52:1499-1505, 2011

28. Roulet-Perez E, Davidoff V, Mayor-Dubois C, Maeder-Ingvar M, Seeck M, Ruffieux C, et al: Impact of severe epilepsy on development: recovery potential after successful early epilepsy surgery. Epilepsia 51:1266-1276, 2010

29. Skirrow C, Cross JH, Cormack F, Harkness W, VarghaKhadem F, Baldeweg T: Long-term intellectual outcome after temporal lobe surgery in childhood. Neurology 76:13301337,2011

30. Smith ML, Elliott IM, Lach L: Cognitive, psychosocial, and family function one year after pediatric epilepsy surgery. Epilepsia 45:650-660, 2004

31. Smith ML, Olds J, Snyder T, Elliott I, Lach L, Whiting S: A follow-up study of cognitive function in young adults who had resective epilepsy surgery in childhood. Epilepsy Behav 32:79-83, 2014

32. Szabó CA, Wyllie E, Stanford LD, Geckler C, Kotagal P, Comair YG, et al: Neuropsychological effect of temporal lobe resection in preadolescent children with epilepsy. Epilepsia 39:814-819, 1998

33. Teutonico F, Mai R, Veggiotti P, Francione S, Tassi L, Borrelli $\mathrm{P}$, et al: Epilepsy surgery in children: evaluation of seizure outcome and predictive elements. Epilepsia 54 (Suppl 7):70-76, 2013

34. Thomas SG, Daniel RT, Chacko AG, Thomas M, Russell
PSS: Cognitive changes following surgery in intractable hemispheric and sub-hemispheric pediatric epilepsy. Childs Nerv Syst 26:1067-1073, 2010

35. Vargha A, Delaney HD: A critique and improvement of the CL common language effect size statistic of McGraw and Wong. J Educ Behav Stat 25:101-132, 2000

36. Vasconcellos E, Wyllie E, Sullivan S, Stanford L, Bulacio J, Kotagal P, et al: Mental retardation in pediatric candidates for epilepsy surgery: the role of early seizure onset. Epilepsia 42:268-274, 2001

37. Westerveld M, Sass KJ, Chelune GJ, Hermann BP, Barr WB, Loring DW, et al: Temporal lobectomy in children: cognitive outcome. J Neurosurg 92:24-30, 2000

38. Wieser HG, Blume WT, Fish D, Goldensohn E, Hufnagel A, King D, et al: ILAE Commission Report. Proposal for a new classification of outcome with respect to epileptic seizures following epilepsy surgery. Epilepsia 42:282-286, 2001

\section{Author Contributions}

Conception and design: Shurtleff, Ojemann. Acquisition of data: Shurtleff, Firman, Warner, Aguilar-Estrada, Ojemann. Analysis and interpretation of data: Shurtleff, Barry, Firman, Ojemann. Drafting the article: Shurtleff, Barry, Ojemann. Critically revising the article: Shurtleff, Barry, Warner, Saneto, Ojemann. Reviewed submitted version of manuscript: Shurtleff, Barry, Warner, Saneto, Kuratani, Ellenbogen, Novotny, Ojemann. Approved the final version of the manuscript on behalf of all authors: Shurtleff. Statistical analysis: Shurtleff, Barry, Ojemann.

\section{Supplemental Information}

Previous Presentation

A portion of this work was presented in poster form at the American Epilepsy Society Annual Meeting on December 2-6, 2011, Baltimore, MD.

\section{Correspondence}

Hillary Shurtleff, Division of Pediatric Neurology, Mail stop MB.7.420, Seattle Children's Hospital, 4800 Sand Point Way NE, Seattle, WA 98105. email: hillary.shurtleff@seattlechildrens.org. 